\title{
Developing a model for application of electronic banking based on electronic trust
}

\author{
Amir Hooshang Nazarpoori ${ }^{a^{*}}$, Reza Sepahvand ${ }^{a}$, Mohamad Cheraghipour ${ }^{b}$ and Akram Nazari Chegini ${ }^{\mathrm{c}}$
}

\author{
${ }^{a}$ Assistant Professor of Business Administration, University of Lorestan, Lorestan, Iran \\ ${ }^{b}$ Master student of Business Management, University of Lorestan, Lorestan, Iran \\ ${ }^{c}$ Master of Educational Psychology, Martyr Chamran University, Ahvaz, Iran \\ C H R O N I C L E

\section{A B S T R A C T}

\section{Article history:}

Received December 28, 2013

Accepted 10 April 2014

Available online

April 142014

Keywords:

Technology-Based Factors

User-Based Factors

Trust

Risk Types

Electronic Banking
This study develops a model for application of electronic banking based on electronic trust among costumers of Day bank in KhoramAbad city. A sample of 150 people was selected based on stratified random sampling. Questionnaires were used for the investigation. Results indicate that technology-based factors, user-based factors, and trust had negative relationships with perceived risk types including financial, functional, personal, and private. Moreover, trust including trust in system and trust in bank had a positive relationship with tendency to use and real application of electronic banking.

\section{Introduction}

With the advent of technology in human life, many changes have been appeared within organizations, which include not only organizational structures, but also the nature and role of business sections (Abedi Jafari et al., 2012). Electronic banking plays essential role for achieving electronic commerce, which in parallel with global monetary and financial systems, facilitates functions and activities of electronic commerce. Application of electronic systems in global finance and credit institutes maintains an increasing trend and the number of users of electronic banking services has been increased over the past two decades. Considering the impressive influence of electronic commerce on global markets together with the importance of credit and monetary exchanges in any type of economical-commercial transaction, it is essential for money exchange tools and contexts to be of acceptable growth along with development of electronic commerce. In this regard, the banks have been active in absorbing more costumers and expanding their services and have adapted themselves with new communication and information technologies. To achieve this, the banks have concentrated

*Corresponding author.

E-mail addresses: ah_nazarpoori@yahoo.com (A. H. Nazarpoori) 
on structural revolution in systems of money receiving and paying and creating facilities provide efficient services. Costumers usually provide their favorable information in their websites and feel bad when they are asked to express their personal information such as credit card number indicating that they were not confident about internet and electronic banking. Trust is a major item for the analysis of exchange transactions. For instance, in trust-commitment relationships in marketing literature, trust is an influencing variable, which results in durable relationships between the parties (Ratnasingham, 1998). It is an intrinsic demand of the costumers to understand the activities of service/product providers because they cannot continue the relationship unless the risk is mitigated. Trust is one of the most effective methods in alleviating the risk among the costumers (Cashell, 1999). In a study entitled "a decision making model based on trust in electronic banking", Kim, Ferrin and Rao (2008) investigated the role of trust and perceived risk and their consequences. The authors found out that there was a significant relationship between costumers' trust and perceived risk with their decision for purchasing from internet (Tajzade Namin et al., 2012). Costumer trust depends on credit, concerns about personal life, concern about security and quality of website information. Teo and Lio (2004) reported that there was a significant correlation between credit and trust to the system and costumers' trust. The costumer' trust was positively associated with attitude and negatively associated with perceived risk (Tajzade Namin et al., 2012). According to Ashtiani et al. (2012) perceived risk is the basis of achieving trust and one of trust consequences is the reduced level of perceived risk in transaction. Based on the explanations mentioned above, trust plays important role in acceptance of electronic banking by the costumers. The main issue is, therefore, that how the trust is formed and how it influences decision-making and application of electronic banking by the costumers. In the present study, the main factors affecting formation of trust in electronic banking and the way in which the resulted trust influences tendency to apply electronic banking is investigated.

\section{Statistical population and sample size}

Statistical population included all costumers of Day bank of Khoram abad during 2012. Stratified sampling was applied as sampling method. Sample size formula depends on investigators need. In the present study, concerning large size of the statistical population and application of principal component analysis technique for data gathering, the number of sample members was assigned as 520 times as much as that of parameters for conformity factor analysis. Since 33 parameters were studied in this investigation, the number of selected sample members was 150, which is seven times as much as that of parameters. Stratified sampling method was used for selection of sample members. Fig. 1 shows educational backgrounds of the people who took part in our survey.

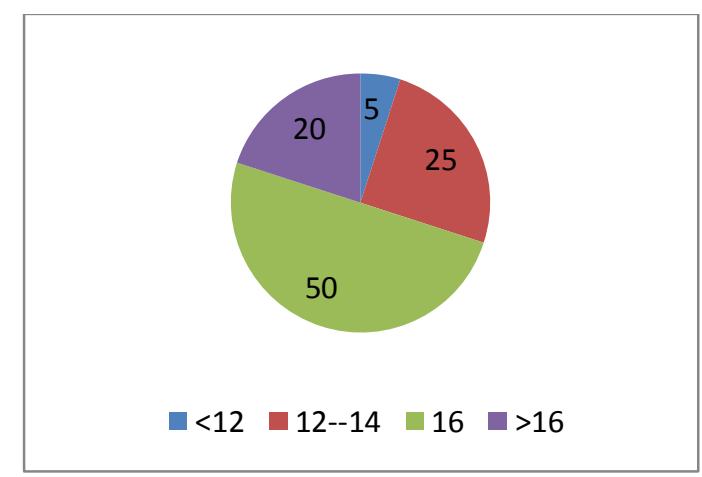

Fig. 1. Personal characteristics of the participants (Years of education)

Library studies and electronic literature investigation were used for gathering theoretical bases of the investigation. Furthermore, questionnaires based on Likert 5 point scale were used to test conceptual model and hypotheses. Since we used standard questionnaires previously applied, all the questionnaire are of appropriate validity. To get confident about the results of questionnaire data 
analysis, reliability of the questionnaires is tested. Reliability means that how similar are the results obtained by the measurement tool in similar conditions. The range of reliability coefficient varies from zero (non correlation between the results obtained by multiple replications of the test in the population) and one (complete correlation between the results of different measurements in the population). There are many ways to calculate dependability. In this investigation, two methods were used: Kuder-Richardson method and Cronbach's alpha method. Table 1 demonstrates the summary of these data.

\section{Table 1}

The summary of KMO and Cronbach alpha

\begin{tabular}{|c|c|c|c|}
\hline Hidden construct & Variable (apparent index) & KMO coefficient & Cronbach's alpha \\
\hline \multirow[t]{3}{*}{ Technology } & Security & 0.86 & \multirow{3}{*}{0.98} \\
\hline & Personal life & 0.77 & \\
\hline & Duty oriented & 0.86 & \\
\hline \multirow[t]{3}{*}{ Applicability } & Perceived usefulness & 0.85 & \multirow{3}{*}{0.96} \\
\hline & Perceived ease of application & 0.96 & \\
\hline & Information quality & 0.88 & \\
\hline \multirow[t]{2}{*}{ Offering } & Complexity abridgement & 0.73 & \multirow[t]{2}{*}{0.69} \\
\hline & Information preparation & 0.91 & \\
\hline \multirow{4}{*}{ Individual factors } & Knowledge and skill & 0.88 & \multirow{4}{*}{0.75} \\
\hline & Innovation & 0.88 & \\
\hline & Involvement & 0.87 & \\
\hline & Risk tolerance & 0.89 & \\
\hline \multirow{3}{*}{ Social factors } & Need to be unique & 0.96 & \multirow{3}{*}{0.96} \\
\hline & Tendency to prestige & 0.91 & \\
\hline & Social penetration & 0.94 & \\
\hline \multirow{4}{*}{ Perceived risk } & Financial risk & 0.95 & \multirow{4}{*}{0.98} \\
\hline & Personal risk & 0.96 & \\
\hline & Duty risk & 0.95 & \\
\hline & Private risk & 0.96 & \\
\hline \multirow{2}{*}{ Trust } & Trust in system & 0.87 & \multirow{2}{*}{0.98} \\
\hline & Trust in bank & 0.86 & \\
\hline \multirow{2}{*}{ Application of banking system } & Tendency to use & 0.89 & \multirow{2}{*}{0.93} \\
\hline & Real use of system & 0.94 & \\
\hline
\end{tabular}

\subsection{Data analysis and hypothesis test}

\subsubsection{Conceptual model}

Inferential and descriptive statistics methods were used for data analysis and hypothesis test. Data gathered by questionnaires were summarized in tables and then, some central and dispersion parameters were calculated. After describing the characteristics of the sample (descriptive statistics) and data classification and abbreviation, statistics of the sample were calculated; parameters of statistic population were then estimated for hypothesis tests. Conceptual model developed based on theoretical principles is presented in Fig. 2.

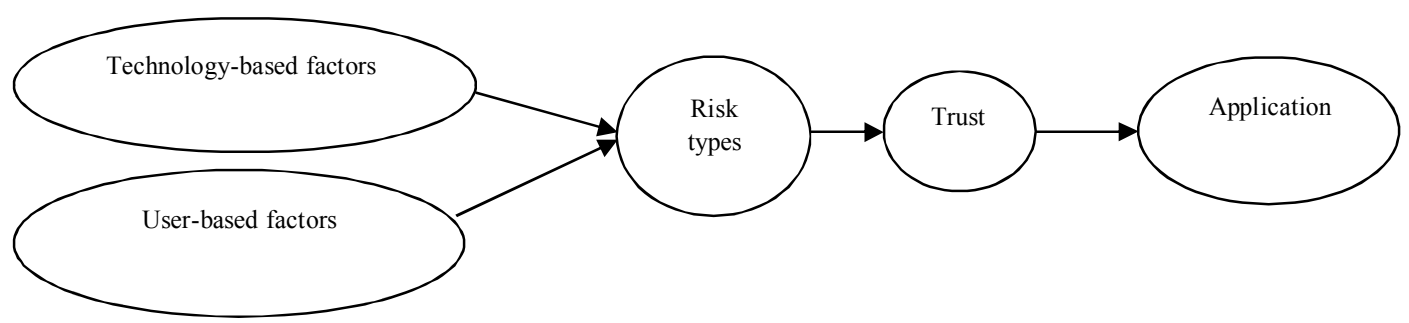

Fig. 2. The proposed study

There are two types of exogenous constructs as well as indigenous constructs used for the proposed study of this paper and Table 2 and Table 3 represents them, respectively. 
Table 2

Exogenous constructs and their measuring indices

\begin{tabular}{|c|c|c|c|}
\hline Component & Variable & Index & Reference \\
\hline \multirow[t]{2}{*}{ User-based factors } & Individual factors & $\begin{array}{l}\text { Knowledge and skill, innovation, change, involvement and risk } \\
\text { tolerance }\end{array}$ & \multirow{2}{*}{$\begin{array}{l}\text { Bearden et al., 1989; } \\
\text { Burger \& Cooper, 1979; } \\
\text { Ho \& Ko, 2008; } \\
\text { Hurt et al., } 1977\end{array}$} \\
\hline & Social factors & Need to be unique, Tendency to prestige and social penetration & \\
\hline \multirow{3}{*}{ Technology-based factors } & Technology & Security, personal life and being duty-oriented & \multirow{3}{*}{$\begin{array}{l}\text { Bearden et al., } 1989 \\
\text { Burger \& Cooper, 1979; } \\
\text { Ho \& Ko, 2008; } \\
\text { Hurt et al., } 1977\end{array}$} \\
\hline & Applicability & $\begin{array}{l}\text { Perceived usefulness, perceived easiness and quality of } \\
\text { information }\end{array}$ & \\
\hline & Information presentation & Abridgement complexity and information preparation & \\
\hline
\end{tabular}

Table 3

Indigenous constructs and their measuring indices

\begin{tabular}{llll}
\hline Component & Variable & Index & Reference \\
\hline Perceived risk & Risk & Financial, personal, duty and private risk & Zhao et al., 2010 \\
Trust & & Trust in system and trust in bank & Chong et al., 2010 \\
Application of electronic banking & & Tendency to application and real application & Zhao et al., 2010; Akinic et al., 2004 \\
\hline
\end{tabular}

\subsection{Hypothesis test method}

In this investigation, conformity factor analysis and structural equations modeling using AMOS and SPSS software were used for resting the hypotheses or testing significance of the questions. Moreover, path analysis technique and structural equation model was used to estimate direct effect of exogenous variables on indigenous variables of the conceptual model.

\subsection{Inferential analysis of data}

\subsubsection{Hypothesis tests}

After evaluation and confirmation of measuring patterns, two partial indices of critical value as CR and $\mathrm{P}$ were used for testing significance of the hypotheses. According to significance level of 0.05 , critical value should be above 1.96 and parameter value lower this critical value is not considered as significant. Moreover $\mathrm{p}$ values lower than 0.05 suggests that value calculated for regression weights equal to zero are significant in 0.95 level. The hypotheses together with regression coefficient and values of partial indices of each hypothesis and fitness indices of the model are presented below.

Hypothesis 1: technological variables (security, privacy and being duty-oriented) have significantly negative relationship with risk types (financial, functional, personal and private).

Fig. 3 shows details of our findings on testing the first hypothesis of the survey

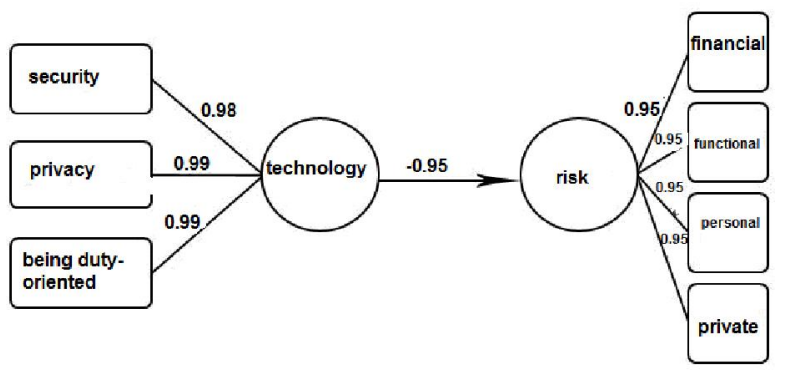

Fig. 3. The results of testing the first hypothesis

Statistical observations associated with the first hypothesis of the survey are summarized in Table 4 as follows, 
Table 4

The summary of statistical observation associated with the first hypothesis

\begin{tabular}{lcccccc}
\hline Statistics & RMSEA & CFI & NFI & IFI & GFI & Chi-Square/df \\
\hline Value & 0.09 & 0.99 & 0.99 & 0.99 & 0.96 & 2.21 \\
\hline
\end{tabular}

The results of Table 4 indicate that all statistical observations are within acceptable level. The standard coefficient for this hypothesis is equal to 0.038 with P-value of 0.001 , which confirms the first hypothesis of this survey and we can conclude that technological variables influence negatively on risk components.

Hypothesis 2: there is a significantly negative relationship between applicability and risk types.

Fig. 4 shows details of our findings on testing the first hypothesis of the survey

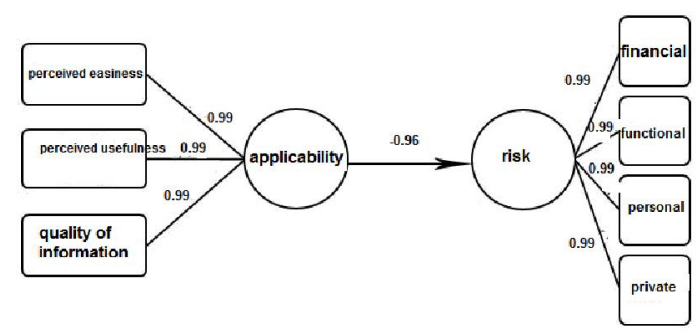

Fig. 4. The results of testing the second hypothesis

Statistical observations associated with the second hypothesis of the survey are summarized in Table 5 as follows,

Table 5

The summary of statistical observation associated with the second hypothesis

\begin{tabular}{lcccccc}
\hline Statistics & RMSEA & CFI & NFI & IFI & GFI & Chi-Square/df \\
\hline Value & 0.09 & 0.99 & 0.99 & 0.99 & 0.95 & 2.13 \\
\hline
\end{tabular}

The results of Table 5 indicate that all statistical observations are within acceptable level. The standard coefficient for this hypothesis is equal to 0.04 with P-value of 0.001 , which confirms the second hypothesis of this survey and we can conclude that there is a significantly negative relationship between applicability and perceived risk types.

Hypothesis 3: There is a significantly negative relationship between information providing and risk types.

Fig. 5 demonstrates details of our findings on testing the third hypothesis of the survey

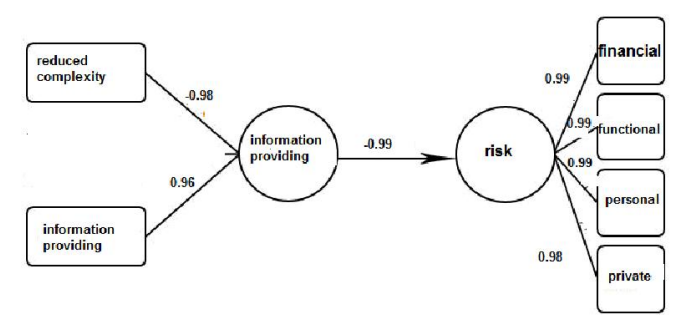

Fig. 5. The results of testing the third hypothesis 
Statistical observations associated with the third hypothesis of the survey are summarized in Table 6 as follows,

Table 6

The summary of statistical observation associated with the third hypothesis

\begin{tabular}{lcccccc}
\hline Statistics & RMSEA & CFI & NFI & IFI & GFI & Chi-Square/df \\
\hline Value & 0.08 & 0.99 & 0.99 & 0.99 & 0.96 & 2.09 \\
\hline
\end{tabular}

The results of Table 6 specify that all statistical observations are within acceptable level. The standard coefficient for this hypothesis is equal to 0.03 with P-value of 0.001 , which confirms the third hypothesis of this survey and we can conclude that there is a significantly negative relationship between information providing and risk types.

Hypothesis 4: there is a significant and negative relationship between individual factors and risk types.

Fig. 6 demonstrates details of our findings on testing the third hypothesis of the survey

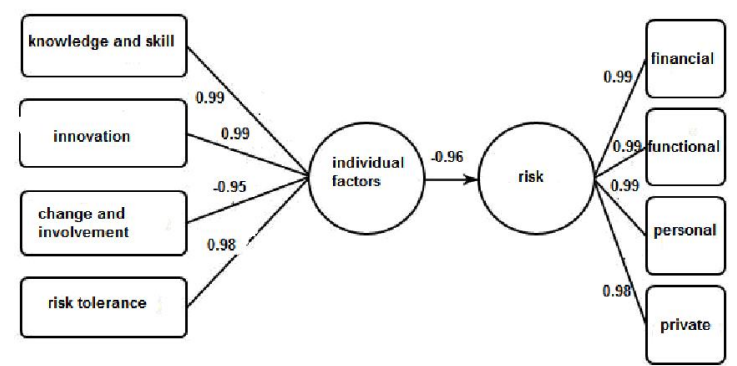

Fig. 6. The results of testing the fourth hypothesis

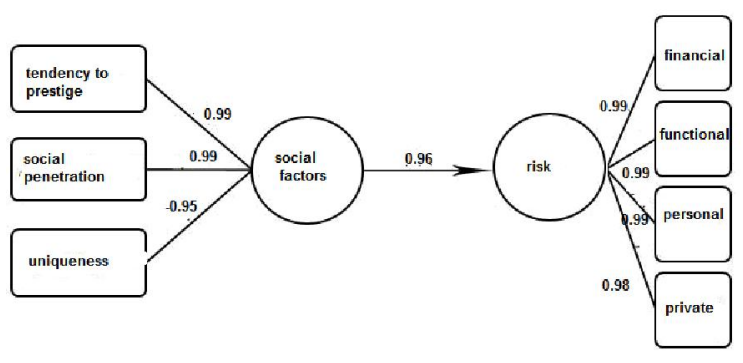

Fig. 7. The results of testing the fifth hypothesis

Statistical observations associated with the fourth hypothesis of the survey are summarized in Table 7 as follows,

Table 7

The summary of statistical observation associated with the fourth hypothesis

\begin{tabular}{lcccccc}
\hline Statistics & RMSEA & CFI & NFI & IFI & GFI & Chi-Square/df \\
\hline Value & 0.09 & 0.99 & 0.99 & 0.99 & 0.94 & 2.27 \\
\hline
\end{tabular}

The results of Table 7 specify that all statistical observations are acceptable. The standard coefficient for this hypothesis is equal to 0.023 with P-value of 0.001 , which confirms the fourth hypothesis of this survey and we can conclude that there is a significant and negative relationship between individual factors and risk types.

Hypothesis 5: social factors have negative effect on risk type.

Fig. 7 demonstrates details of our findings on testing the fifth hypothesis of the survey and Statistical observations associated with the fourth hypothesis of the survey are summarized in Table 8 as follows,

Table 8

The summary of statistical observation associated with the fifth hypothesis

\begin{tabular}{lcccccc}
\hline Statistics & RMSEA & CFI & NFI & IFI & GFI & Chi-Square/df \\
\hline Value & 0.05 & 0.99 & 0.99 & 0.99 & 0.94 & 1.47 \\
\hline
\end{tabular}


The results of Table 8 specify that all statistical observations are acceptable. The standard coefficient for this hypothesis is equal to 0.025 with $\mathrm{P}$-value of 0.001 , which confirms the fifth hypothesis of this survey and we can conclude that there is a significant and negative relationship between individual factors and risk types.

Hypothesis 6: Risk types have negative impact on trust in bank.

Hypothesis 7: Risk types have negative impact on trust in system.

Fig. 8 and Fig. 9 show details of SEM model for testing the sixth and seventh hypotheses.

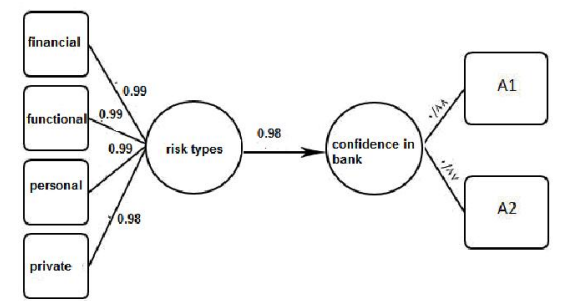

Fig. 8. The results of testing the sixth hypothesis

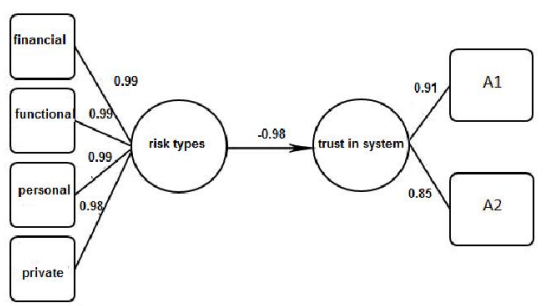

Fig. 9. The results of testing the seventh hypothesis

In addition, statistical observations associated with the sixth and seventh hypotheses of the survey are summarized in Table 9 as follows,

\section{Table 9}

The summary of statistical observation associated with the sixth and seventh hypothesis

\begin{tabular}{lcccccc}
\hline Statistics & RMSEA & CFI & NFI & IFI & GFI & Chi-Square/df \\
\hline Value (Hyp. 6) & 0.08 & 0.99 & 0.99 & 0.99 & 0.97 & 2.10 \\
Value (Hyp. 7) & 0.08 & 0.99 & 0.99 & 0.99 & 0.97 & 1.97 \\
\hline
\end{tabular}

The results of Table 9 specify that all statistical observations are acceptable. The standard coefficients for the sixth and seventh hypotheses are equal to 0.012 and 0.011 with P-value of 0.001 , respectively, which confirms these two hypotheses of this survey and we can conclude that risk types have negative impact on trust in bank as well as on trust in system.

Hypotheses 8 and 9: trust in bank is positively related to tendency to application and real application.

Hypotheses 10 and 11: trust in system has positive impact on tendency to application and real application.

Fig. 10 and Fig. 11 show details of SEM model for testing the $8^{\text {th }}-9^{\text {th }}$ and $10^{\text {th }}-11^{\text {th }}$ hypotheses.

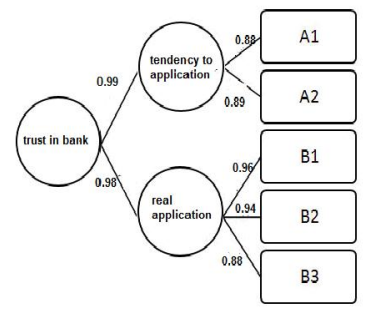

Fig. 10. The results of testing the $8^{\text {th }}-9^{\text {th }}$ hypotheses

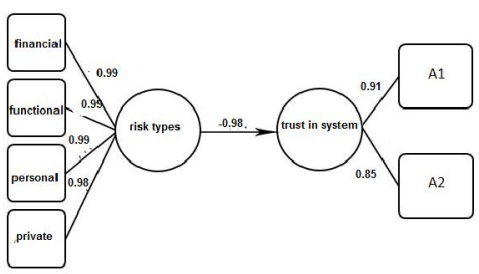

Fig. 11. The results of testing the $10^{\text {th }}-11^{\text {th }}$ hypotheses 
In addition, statistical observations associated with the sixth and seventh hypotheses of the survey are summarized in Table 10 as follows,

Table 10

The summary of statistical observation associated with the $8-11^{\text {th }}$ hypotheses

\begin{tabular}{lcccccc}
\hline Statistics & RMSEA & CFI & NFI & IFI & GFI & Chi-Square/df \\
\hline Value (Hyps. 8-9) & 0.09 & 0.99 & 0.99 & 0.99 & 0.96 & 3.00 \\
Value (Hyps. 10-11) & 0.08 & 0.99 & 0.99 & 0.99 & 0.97 & 2.26 \\
\hline
\end{tabular}

The results of Table 9 specify that all statistical observations are acceptable. The standard coefficients for the sixth and seventh hypotheses are equal to 0.016 and 0.014 with P-value of 0.001 , respectively, which confirms these four hypotheses of this survey.

\section{Discussion and conclusion}

The results of the first hypothesis are in agreement with those reported by Hoffman et al. (1999), Madhooshi et al. (2005), Mahmoodi Meimand et al. (2009) and Moradi et al. (2010). If people feel no risk in use of bank, are not concerned about disclosure of their personal and private information and application of electronic banks and systems results in saving of time and reduction of stress, these factors reduce private, financial, personal and functional risk types.

Results of the second hypothesis agree with those reported by Abrazovic (2004), Suh and Han (2002), Madhooshi et al. (2005) and Moshiri and Jonaidi (2007). When costumers feel that the system and bank they use enhance their function, application of this banking system does not demand much affair. Therefore, they can use the bank easily and they have trust on the bank and the system, then the costumers use this banking system for applications such as account transfer and so on with lower level of concern and provide their personal and private information for the bank with higher feeling of security.

The results of third hypothesis are in agreement with those reported by Weedman et al. (2010). When the system has lower complexity and use of electronic banking needs no additional tool and understanding system and banking details is easy, people understand processes and information of the system and have sufficient information for application of the system, perceived risk is lowered and exploiting the electronic system and banking is performed with lower horror.

The result of fourth hypothesis is in agreement with those obtained by Xao et al. (2010) and Weedman et al. (2010). An important obstacle in acceptance and application of modern systems and technology is lacking of knowledge about application of the systems. Many citizens may tend to use these systems but are not familiar with application of the systems or are not provided with necessary education (Negi et al., 2007). Knowledge and skill in exploiting electronic banking leads to application of correct processes such as proper methods of money transfer, entering account number, appropriate reaction in the time of entering wrong accounting number, using unidentifiable ciphers, etc. and so the perceived risk is lowered.

Creative people are highly eager to exploit new methods and technologies and accept the corresponding risk more easily. About change and involvement issue, it can be maintained that one can accept the risk of changes when he/she accepts the changes more rapidly and get involved in modern technology more extensively. Higher risk tolerance means that the person is braver and accepts the risk of investment and application of modern technology and use electronic banking as a modern technology without any fear. 
The results of fifth hypothesis are in agreement with those reported by Jiffen and Strab (2000), Mokharji and Noth (2003), and Gorrow et al. (2007). Any tool or new technique, which creates the feeling of usefulness and uniqueness in person by which the person feels that the technique has made $\mathrm{him} /$ her unique among other people, this causes the person to ignore the risk of that technique or tool. Human is a social organism and is influenced by society and his/her friends who can encourage $\mathrm{him} /$ her to perform a task. Based on this, when others use electronic banking and systems, they perceive its advantages more than its risk so encourage other persons to use electronic systems.

The results of hypotheses 7 and 8 are in agreement with those reported by Ashtiani et al. (2012), Teo and Leo (2004) and Kim et al. (2008). In electronic banking, higher risk is perceived because the banks and the clients are separated, this influences costumer's trust. Trust is an important catalyst in transactions. When trust is conceptualized as an aspect of technology acceptance, it can play a critical role in encouraging the users to participate in internet money exchange practices. Trust is a major way of mitigating the risk.

The results of hypotheses 8,9,10 and 11 are agreement with those reported by Yousefzay et al. (2003), Moshiri and Jonaidi (2007) and Bakhshali et al. (2010). Trust has been introduced as the heart of electronic banking system, which influences user's behavior and determines success of modern technologies (Chang et al., 2010). When there is trust on ability of bank for providing banking services, the costumers are encouraged to use these services. Trust makes users feel that the bank is able to provide electronic banking services which finally results in more exploitation of electronic banking. A limitation of the present study is that it is only concentrated on Day bank of Khoram abad and caution should be taken when generalizing the results to other banks.

Concerning huge investment in development of banking systems, it should be determined that many people use these systems. To enhance costumers' use of electronic banking services, there should be systems working with which is easy and they should be advantageous for costumers.

If bank announces a privacy policy or the privacy policy of the bank is confirmed by a third party, the costumers believe that the bank is serious in ethical issues (belief in accuracy). This enhances costumer's tendency to provide personal information for bank (intention of trust). If a person has the intention to share personal information, he/she will probably do the task (internet behaviors related to trust-information sharing).

\section{References}

Abrazhevich, D. (2004). Electronic payment systems: A user-centered perspective and interaction design. Dennis Abrazhevich.

Akinci, S., Aksoy, S., \& Atilgan, E. (2004). Adoption of internet banking among sophisticated consumer segments in an advanced developing country. International Journal of Bank Marketing, 22(3), 212-232.

Abedi Jafari, H., Asadnejad Rokni, M., \& Yazdani, H. (2012). Investigating effect of Information technology on strategic performance of human resource section in car manufacturing firms. Journal of technology management, (3).3.

Bearden, W. O., Netemeyer, R. G., \& Teel, J. E. (1989). Measurement of consumer susceptibility to interpersonal influence. Journal of consumer research, 473-481.

Burger, J. M., \& Cooper, H. M. (1979). The desirability of control. Motivation and emotion, 3(4), 381-393.

Bakhshali, F., Hosseini fard, S.M., Rahmati, M.H. (2010). investigating the effects of influencing factors on acceptance of electronic banking (case study: Melli bank of Arak province). Management of organizational culture, 22, 147-168.

Cashell, J. D. (1999). Web trust: A seal of approval. The Internal Auditor, 56(3), 50-53. 
Chong, A. Y. L., Ooi, K. B., Lin, B., \& Tan, B. I. (2010). Online banking adoption: an empirical analysis. International Journal of Bank Marketing, 28(4), 267-287.

Guerrero, M., Egea, O., \& Gonzales, M. (2007). Application of the latent class regression methodology to analysis of internet use for banking transaction in the European union. Journal of Business Research, 60, 137-145

Gefen, D., \& Straub, D. W. (2000). The relative importance of perceived ease-of-use in Is adoption: A study of e-commerce adoption. Journal of the Association for Information System, 3, 27-51.

Ghaffari Ashtiani, P., Zanjirdar, M., \& Shabani, R. (2012). Effect of trust and perceived risk on electronic banking services among costumers of Arak banks. Journal of Business management, $16,41-61$.

Ho, S. H., \& Ko, Y. Y. (2008). Effects of self-service technology on customer value and customer readiness. Journal of Internet Research, 18(4), 427-446.

Hoffman, D. L., Novak, T. P., \& Peralta, M. A. (1999). Beyond consumer trust online. Communications of the ACM, 42(4), 80-85.

Hurt, H. T., Joseph. K., \& Cook, C. D. (1977). Scales for the measurement of innovativeness. Journal of Human Communication Research, 4(1), 58-65.

Mukherjee, A., \& Nath, P. (2003). A model of trust in online relationship banking. International Journal of Bank Marketing, 21(1), 5-12.

Madhooshi, M., Zali, M., \& Raouf Emami, M. (2009). Evacuating different types of electronic payment from Iranian costumers' view. Journal of Social and Human Science. 5(19), 65-96.

Mahmoodi Meimand, M, Dehkordi, L., \& Ahmadinejad, M. (2009). Acceptance pattern of internet bank by costumers. Business Management Investigation, 1-30

Moradi, M., Zendehdel, A., \& Serjanian, Z. (2010). investigating effects of risk and perceived uncertainty on application of internet banking. $2^{\text {nd }}$ International Conference on financial Services Marketing, 1-16.

Moshiri, M., \& Jonaidi, M. (2007). investigating effect costumers' trust on acceptance of internet banking based on TIM in Tehran (case study: Mellat bank). $5^{\text {th }}$ International Conference of Management, 1-20.

Nagi, E. W. T., Poon, J. K. L., \& Chan, Y. H. C. (2007). Empirical examination of the adoption of web CT Using TAM. Computers \& Education, 48, 250-267.

Ratnasingham, P. (1998). The importance of trust in electronic commerce. Internet Research: Electronic Networking Applications and Policy, 8 (1), 313-321.

Suh, B., \& Han, I. (2002). Effect of trust on customer acceptance of internet banking. Electronic eCommerce Research and Applications, 1, 242-263.

Tajzadeh Namin, A. A ., Rangriz, H. \& Akbariyeh, H. (2012). Evaluating electronic trust in payment internet banking. Journal of Basic and Applied Scientific Research, 2(4), 3339-3348.

Zhao, A. L., Koenig-Lewis, N., Hanmer-Lloyd, S., \& Ward, P. (2010). Adoption of internet banking services in China: Is it all about trust? International Journal of Bank Marketing, 28(1), 7-26. 